\title{
"SABORES E DISSABORES" DE UMA HORTA ESCOLAR: PERCEPÇÕES GUSTATIVAS E VIVÊNCIAS DE ALUNOS DO ENSINO FUNDAMENTAL
}

\author{
"SWEETNESS AND BITTERNESS" OF A SCHOOL VEGETABLE \\ GARDEN: GUSTATORY PERCEPTIONS AND EXPERIENCES OF \\ ELEMENTARY SCHOOL STUDENTS
}

\author{
Luan Hugolino de Moraes (luanhdm2@ gmail.com) \\ Universidade do Estado do Rio de Janeiro, Faculdade de Formação de Professores, Especialização em \\ Educação básica - modalidade Ensino de Biologia \\ Marcelo Guerra Santos (marceloguerrasantos@gmail.com) \\ Universidade do Estado do Rio de Janeiro, Faculdade de Formação de Professores, Núcleo de Pesquisa e \\ Ensino de Ciências
}

Resumo: As hortas escolares são ambientes propícios para abordar o tema educação alimentar, sendo favoráveis para estimular uma alimentação mais saudável no cotidiano dos alunos. O comportamento alimentar pode ser determinado pela percepção individual do paladar, somado a estrutura socioeconômica, influência da mídia e hábitos alimentares de seus responsáveis. Este trabalho teve como principal objetivo avaliar a percepção que os alunos do ensino fundamental II possuem sobre uma horta e a preferência alimentar deles pelas plantas cultivadas. Com a participação dos alunos, foi montada uma horta na escola. Por meio de um questionário, foram adquiridas informações sobre a vivência dos alunos com hortas, percepção gustativa e em relação à saúde e ao meio ambiente. Do total de alunos, $40 \%$ afirmaram possuir ou já ter tido uma horta em sua casa. A maioria dos alunos nunca havia experimentado os vegetais plantados na horta escolar. Eles indicaram o uso do agrotóxico utilizado nos vegetais comercializados como a principal diferença entre os vegetais cultivados em hortas caseiras. Foi possível observar neste trabalho a importância de se utilizar uma horta como ferramenta pedagógica para explorar a percepção dos alunos sobre saúde e meio ambiente e ampliar os seus conhecimentos.

Palavras-chave: Horta escolar; Alimentação saudável; Percepção ambiental

\begin{abstract}
School vegetable gardens are favorable environments to address the issue of food education, being favorable to stimulate a healthier diet in the daily lives of students. The food behavior can be determined by the individual perception of the palate, added to as socioeconomic structure and influence of the media and the eating habits of their guardians. This work had as main objective to evaluate the perception that elementary
\end{abstract}


school students have about a garden and their preference for the cultivated plants. With the students' participation, a vegetable garden was set up. Through a questionnaire was acquired information about the students' experience with vegetable gardens, gustatory perception and relation to health and the environment. Of the total number of students, $40 \%$ reported having or already had a vegetable garden in their home. The majority of the students had never tried the vegetables planted in the school vegetable garden. The students related the use of pesticide on the commercialize vegetables as the main difference between vegetables growing in home gardens and those sold. It was possible to observe in this work the importance of using a vegetable garden as a pedagogical tool to explore the student's perception about health and the environment and to broaden their knowledge.

Keywords: school vegetable garden; healthy eating; environmental perception

\section{INTRODUÇÃO}

De acordo com a Base Nacional Comum Curricular - BNCC (BRASIL, 2017):

[...] cabe aos sistemas e redes de ensino, assim como às escolas, em suas respectivas esferas de autonomia e competência, incorporar aos currículos e às propostas pedagógicas a abordagem de temas contemporâneos que afetam a vida humana em escala local, regional e global, preferencialmente de forma transversal e integradora.

Entre esses temas, estão a educação ambiental, e a educação alimentar e nutricional. Os Parâmetros Curriculares Nacionais - PCNs (BRASIL, 1997) já preconizavam que os conteúdos em educação ambiental e saúde deveriam ser trabalhados na escola com transversalidade, para que os alunos possam utilizar seus conhecimentos escolares em sua vida extraescolar. Esses conteúdos não pertencem a uma disciplina específica, mas sim, deverão ser abordados de forma integrada e contínua.

A educação ambiental surgiu como uma das maneiras de se diminuir a degradação da natureza. Essa ideia é resultante dos debates em eventos mundiais promovidos pela ONU para a discussão de políticas e acordos ambientais, com o objetivo de entender e minimizar os impactos ambientais (CRIBB, 2010). Nas palavras de Cribb (2010, p. 4) “[...] a educação ambiental surge como um processo educativo que conforma um conhecimento ambiental que se traduz em valores éticos". 
Segundo Miranda et al. (2011), tem se atribuído à escola um papel de destaque na educação ambiental dos sujeitos. Entretanto, Tristão (2004) alerta que dentro de um contexto de educação ambiental, a racionalidade técnica e instrumental pode comprometer uma atuação mais reflexiva e problematizadora. Essa autora afirma que é preciso "pensar de outra maneira", ou seja, não se trata de aprender uma quantidade enorme de coisas, mas sim sobre "os problemas que se apresentam no cotidiano, estabelecer vínculos e conexões para tornar significativo o processo de aprendizagem". De acordo com Viégas; Guimarães (2004), os professores precisam inserir processos de sensibilização em suas práticas pedagógicas com os alunos. Essas autoras destacam:

[...] o ser humano não é só razão, cérebro, mas também emoção, coração, e, de diversas formas, procuram sensibilizar e emocionar seus alunos para a beleza, a paz, a harmonia do natural: as vivências e visitas aos lugares com beleza natural, os trabalhos com artes, etc.

A horta dentro do ambiente escolar pode ser capaz de estreitar a relação dos alunos com a natureza, trazendo contribuições para o processo educativo e sensibilização para a temática ambiental. Segundo Tibolla; Nactigall (2014),

\footnotetext{
A horta escolar é uma estratégia de educar para o ambiente, para a alimentação e para vida, na medida em que oportuniza que tais princípios sejam colocados em prática e incorporados à formação dos cidadãos em idade escolar.
}

Uma horta escolar pode se tornar um laboratório vivo, um ambiente onde se une teoria e prática com atividades contextualizadas, promovendo um melhor processo de ensino/aprendizagem e maior interação com o grupo através do trabalho coletivo (PIMENTA; RODRIGUES, 2011), sendo capaz de propiciar novas aprendizagens tanto nos professores quanto nos alunos (TIBOLLA; NACTIGALL, 2014). Adicionalmente, ela pode ser uma ótima estratégia que possibilite o aumento do consumo de hortaliças, promovendo mudanças para hábitos alimentares mais saudáveis nos alunos (MUNIZ; CARVALHO, 2007).

É observado um crescimento no consumo de alimentos de alta densidade calórica e maior concentração energética, através da produção de alimentos relativamente baratos pela indústria de alimentos (MONTEIRO; CASTRO, 2009). Os hábitos 
alimentares estão estritamente relacionados à saúde humana. Um mau hábito alimentar, dentre outros fatores, está associado ao crescimento da obesidade infantil e outras doenças (ALMEIDA; NASCIMENTO; QUALOTI, 2002).

Alguns hábitos, assim como o alimentar, são formados no período da infância. A elaboração de projetos educativos baseados nos processos determinantes desses hábitos pode ser efetiva para contribuir na mudança de comportamentos que serão refletidos na vida adulta (BISSOLI; LANZILLOTTI, 1997).

São diversas as atividades pedagógicas que podem ser trabalhadas a partir de uma horta escolar e estão relacionados aos conteúdos/conceitos de Ciências, tais como, plantas, usos do solo, consumo consciente, reciclagem, nutrição do organismo e hábitos alimentares (BRASIL, 2017). De acordo com Neves (2006), podem ser atendidos os seguintes objetivos: valorizar a importância do trabalho e cultura do homem do campo; identificar técnicas de manuseio do solo e manuseio sadio dos vegetais; conhecer técnicas de cultura orgânica; estabelecer relações entre o valor nutritivo dos alimentos cultivados; compreender a relação entre solo, água e nutrientes; identificar processos de semeadura, adubação e colheita; cooperar em projetos coletivos; compreender a importância de uma alimentação equilibrada para a saúde.

Diante do crescimento no consumo de alimentos de alta densidade calórica, que pode gerar maus hábitos alimentares durante a infância; a construção de uma horta possibilita o contato direto dos alunos com o cultivo de vegetais e a produção de alimentos, podendo contribuir para mudanças em seus hábitos alimentares. Desse modo, o presente estudo teve como objetivos (1) montar uma horta escolar junto com os alunos; (2) avaliar a vivência dos alunos com hortas; (3) registrar a percepção gustativa dos alunos em relação às plantas propostas para o cultivo na horta; (4) analisar a percepção que os alunos têm a respeito das plantas cultivadas em hortas caseiras e vegetais comercializados, em relação à saúde e ao meio ambiente.

\section{METODOLOGIA}




\section{Cenário de realização da pesquisa}

As atividades foram desenvolvidas com 61 alunos do sexto ano do ensino fundamental II do Colégio Santa Mônica Centro Educacional, escola particular situada no bairro Cascadura, município do Rio de Janeiro, estado do Rio de Janeiro, durante o segundo semestre do ano letivo de 2017.

Neste trabalho, os alunos que formam o campo empírico da pesquisa foram alunos do primeiro autor, cujo intuito era alcançar melhorias nas suas práticas de ensino, caracterizando-se assim como uma pesquisa-ação. Segundo Tripp (2005), estes estudos se caracterizam da seguinte forma:

A pesquisa-ação educacional é principalmente uma estratégia para o desenvolvimento de professores e pesquisadores de modo que eles possam utilizar suas pesquisas para aprimorar seu ensino e, em decorrência, o aprendizado de seus alunos.

O trabalho dentro desta categoria possui um caráter investigativo com uma troca mútua entre pesquisador e o campo empírico da pesquisa, para gerar soluções aos problemas detectados (THIOLLENT, 2007). Para Alarcão (2010), os alunos devem ser capacitados a serem críticos e reflexivos e, desse modo, aptos a opinarem sobre as informações que lhes são transmitidas. Por meio da investigação-ação a reflexão se torna mais frequente e possível nos processos formativos (PERSON; GÜLLICH, 2013).

As situações didáticas planejadas devem estar atreladas ao processo investigativo promovendo, através do ensino de ciências, ações de intervenção para melhorar a qualidade de vida individual, coletiva e socioambiental. (BRASIL, 2017)

\section{Montagem da horta}

Para a montagem da horta foram reutilizados caixotes de madeira de feiras urbanas. Eles foram usados para fazer o plantio das hortaliças, pois nas dependências da escola não havia disponibilidade de solo. As mudas das hortaliças e a terra adubada para a preparação do substrato foram adquiridas no comércio. Além disso, os alunos foram convidados a contribuir com doações de insumos (terra adubada) para a horta.

A preparação da horta foi realizada pelos alunos, com a orientação do professor a respeito de todos os cuidados necessários, tais como o plantio e a rega. Foram 
selecionadas onze hortaliças, dentre elas, alface, alface roxa, acelga, chicória, agrião, espinafre, rúcula, tomate, coentro, salsa e salsão.

Foi solicitada aos alunos a produção de cartazes identificando os benefícios que as hortaliças da horta escolar podem trazer à saúde através do seu consumo regular, uma vez que o envolvimento afetivo e lúdico estimulado durante as práticas de educação ambiental são de grande importância para o processo de ensinoaprendizagem (BARCELOS, 2008).

\section{Coleta dos dados}

Os alunos foram convidados a preencher um questionário (Anexo 1) para uma sondagem de suas experiências com a montagem da horta escolar e os alimentos cultivados nela. As respostas tiveram o seu conteúdo analisado e categorizado. De acordo com SILVA et al. (2005), na análise de conteúdo de Laurence Bardin é feita a

identificação de unidades de análise ou grupos de representações para uma
categorização dos fenômenos, a partir da qual se torna possível uma
reconstrução de significados que apresentem uma compreensão mais
aprofundada da interpretação de realidade do grupo estudado.

As respostas foram organizadas em categorias de acordo com o grau de similaridade dos conteúdos nelas descrito.

Após o questionário os alunos tiveram acesso a conteúdos teóricos em sala de aula sobre alimentação saudável, utilização de agrotóxicos e suas consequências no ambiente.

\section{RESULTADOS E DISCUSSÃO}

\section{Cenário de realização da pesquisa}

A atividade foi desenvolvida em duas turmas de sexto ano do Santa Mônica Centro Educacional, uma turma do turno da manhã com 34 alunos, sendo 15 meninos e 19 meninas, e a outra no turno da tarde com 27 alunos, sendo 10 meninos e 17 meninas. O quantitativo de todos os alunos das duas turmas é de 61 alunos. 
Todos os alunos, das duas turmas, participaram das atividades. Apenas um aluno, da turma da tarde, mostrou resistência por não querer participar do plantio, mas no final da atividade, ao ver os colegas empolgados e fazendo bons comentários, se animou e mudou de ideia participando também da atividade.

\section{A montagem da horta}

No espaço físico da escola os caixotes foram agrupados em quantidades iguais para cada turma, sendo um grupo de 27 caixotes para a turma da manhã e separadamente outro grupo de 36 caixotes para a turma da tarde (Figura 1)

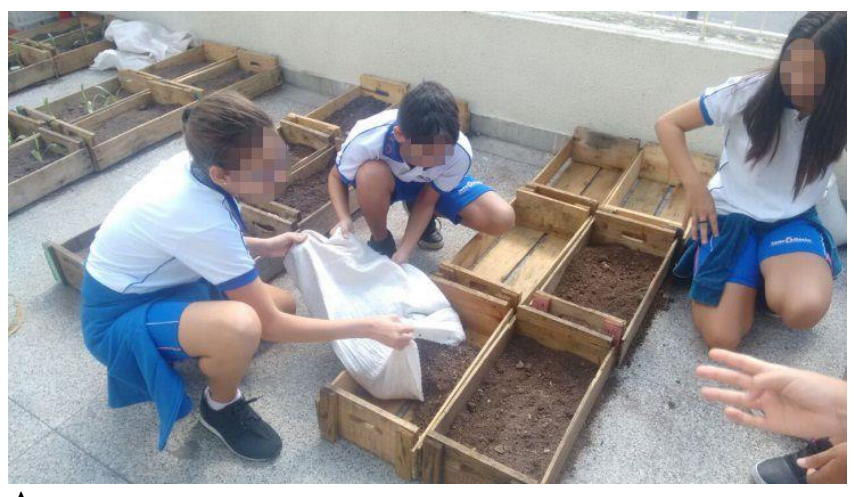

A

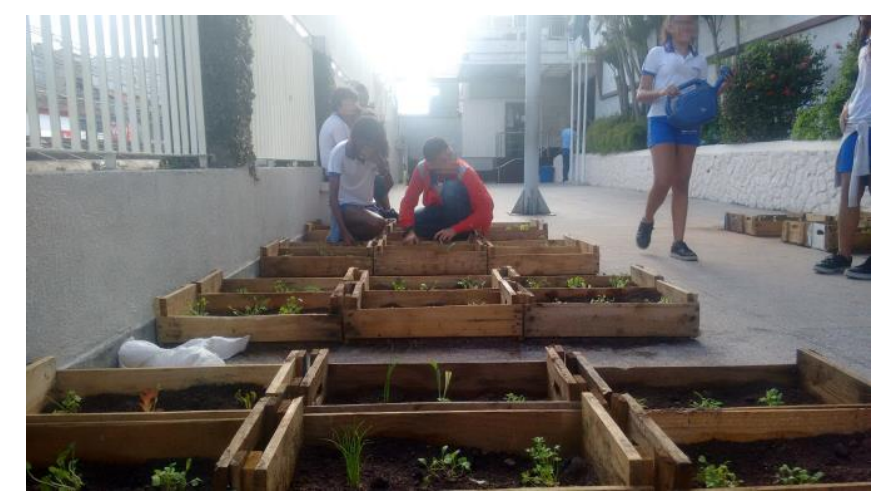

B

Figura 1 - A: Alunos preparando os caixotes para o plantio. B: Alunos realizando o plantio das hortaliças.

As turmas fizeram a atividade de montagem em dias diferentes, de acordo com a data em que coincidiam as aulas de ciências de cada turma. Para a atividade, as turmas foram divididas em grupos de no máximo 10 alunos, para que um grupo de cada vez fizesse o preparo da terra e o plantio, visando ter um melhor aproveitamento do grupo e maior atenção dos alunos às atividades.

Os alunos despejaram a terra adubada dentro dos caixotes. As mudinhas estavam em uma bandeja sementeira, de onde os alunos retiraram para fazer o transplante. Cada aluno fez o plantio de 3 a 4 mudinhas. Dependendo do tipo de hortaliça e de seu desenvolvimento, plantaram-se duas ou três mudas por caixote (Figura 1B). 
Durante as atividades os alunos agiram de forma bastante interativa. Muitos haviam plantado pela primeira vez e se mostraram bastante interessados. A atividade prática fora da sala de aula, utilizando outras dependências da escola, induziu uma mudança de comportamento dos alunos, estimulando a uma maior curiosidade e atenção às suas práticas e às orientações do professor. A preparação da horta foi considerada de baixo nível de dificuldade. Os alunos plantaram com as próprias mãos, fazendo os berçários (buraco realizado para o plantio das mudas) diretamente na terra. Para o professor este tipo de atividade gera grande satisfação pelas reações de alegria e interesse dos alunos.

\section{Cartazes produzidos pelos alunos}

As turmas foram separadas em quatro grupos, dependendo da turma formaram-se grupos de 5 a 7 alunos. Os grupos apresentaram suas pesquisas sobre as propriedades das hortaliças e seus impactos na saúde. Em sala de aula, o professor apresentou uma série de fotos selecionadas na internet, das hortaliças plantadas na horta, e solicitou aos alunos que fizessem a correlação entre o nome de cada hortaliça com as imagens apresentadas. Os alunos tiveram maior dificuldade em reconhecer a chicória e a acelga. Em seguida, os alunos utilizaram o conteúdo de suas pesquisas e a atividade em sala de aula para produzir cartazes sobre a temática (Figura 2).

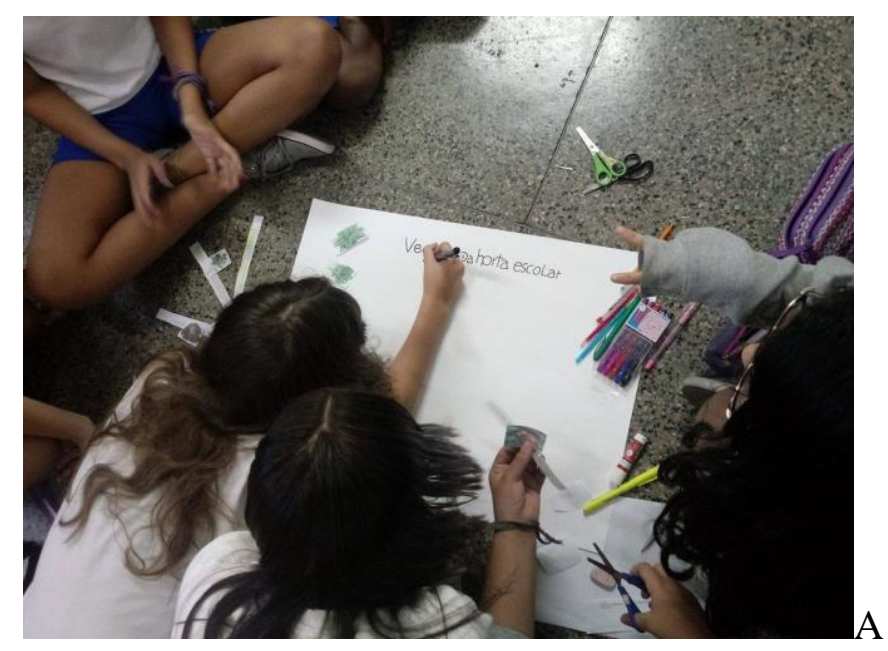




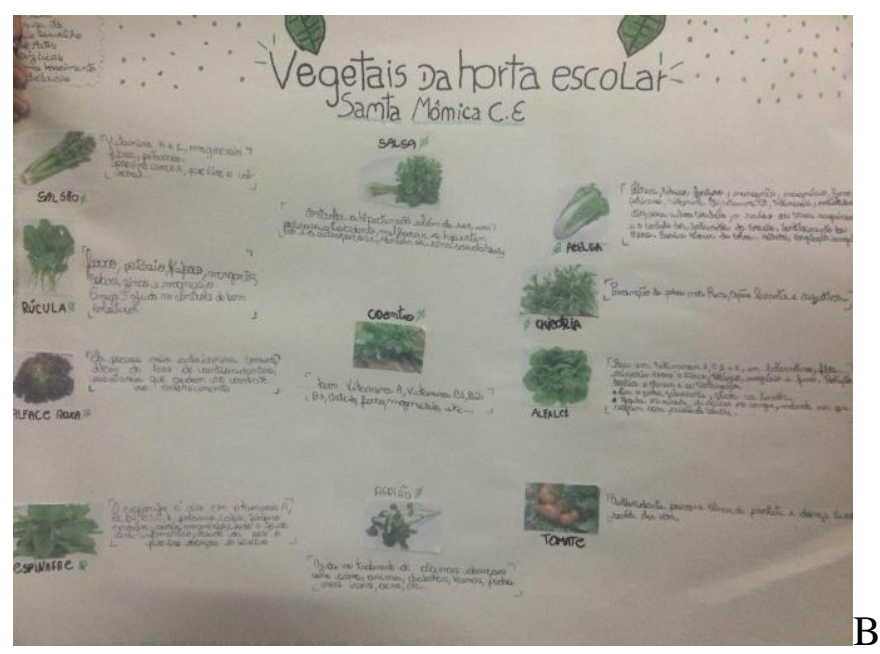

Vol. 2, n. 4. Set./Dez. 2019

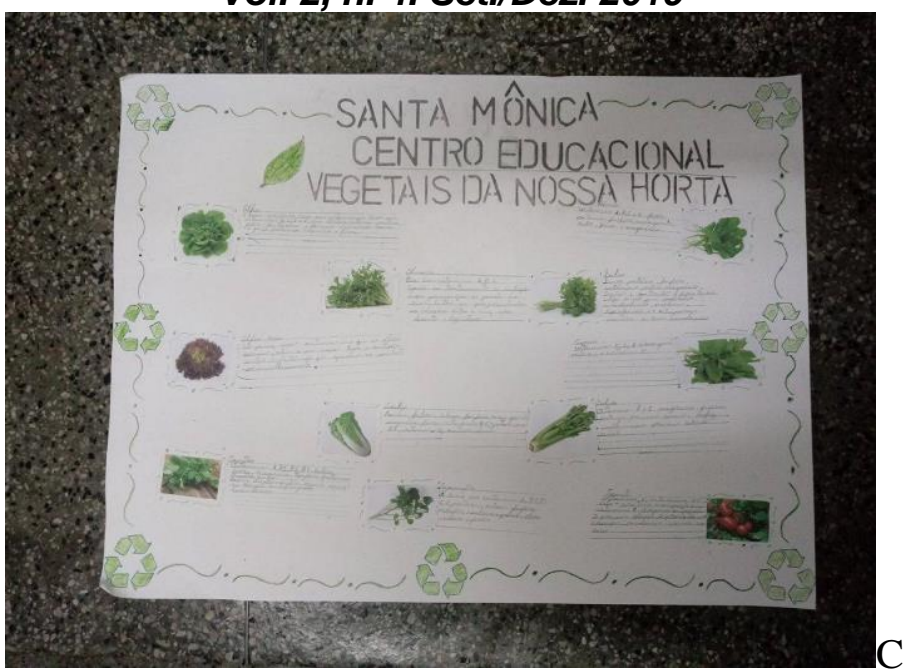

Figura 2 - Produção dos cartazes pelos alunos. A: Alunos montando os cartazes. B: Cartaz relacionando os vegetais da horta com suas propriedades alimentícias. C: Cartaz finalizado produzido pelos alunos do sexto ano.

\section{A vivência dos alunos com uma horta}

Dos 61 alunos, 24 afirmaram possuir ou já ter tido uma horta em sua casa. Dos 37 restantes, os principais motivos para não possuírem uma horta foram a falta de espaço e de tempo para os cuidados necessários. Segundo Freitas et al. (2012), o quintal é um espaço relevante pois é nessa área onde são cultivadas as plantas para os mais variados usos. Entretanto, em diferentes meios de comunicação são apresentadas alternativas para o plantio em espaços reduzidos ou mesmo dentro de casa e apartamentos. Com o espaço físico adequado para o plantio participativo da criança, pode haver uma sensibilização que fomente o interesse para novas experimentações dos vegetais como alimento. Desse modo, a escola é um espaço propício para catalisar essas práticas e atuar como agente disseminador.

Transtornos com a irrigação da horta, principalmente nos finais de semana, ocasionaram a morte das plantas cultivadas, como consequência, infelizmente os alunos não tiveram a oportunidade de saborear a plantas cultivadas por eles.

\section{Percepção do paladar}

De acordo com as suas experiências gustativas, os alunos foram questionados sobre o que achavam dos vegetais plantados na horta escolar, ou seja, deveriam opinar 
indicando os "vegetais que gosto", "vegetais que não gosto" e "vegetais que nunca experimentei” (Figura 3).

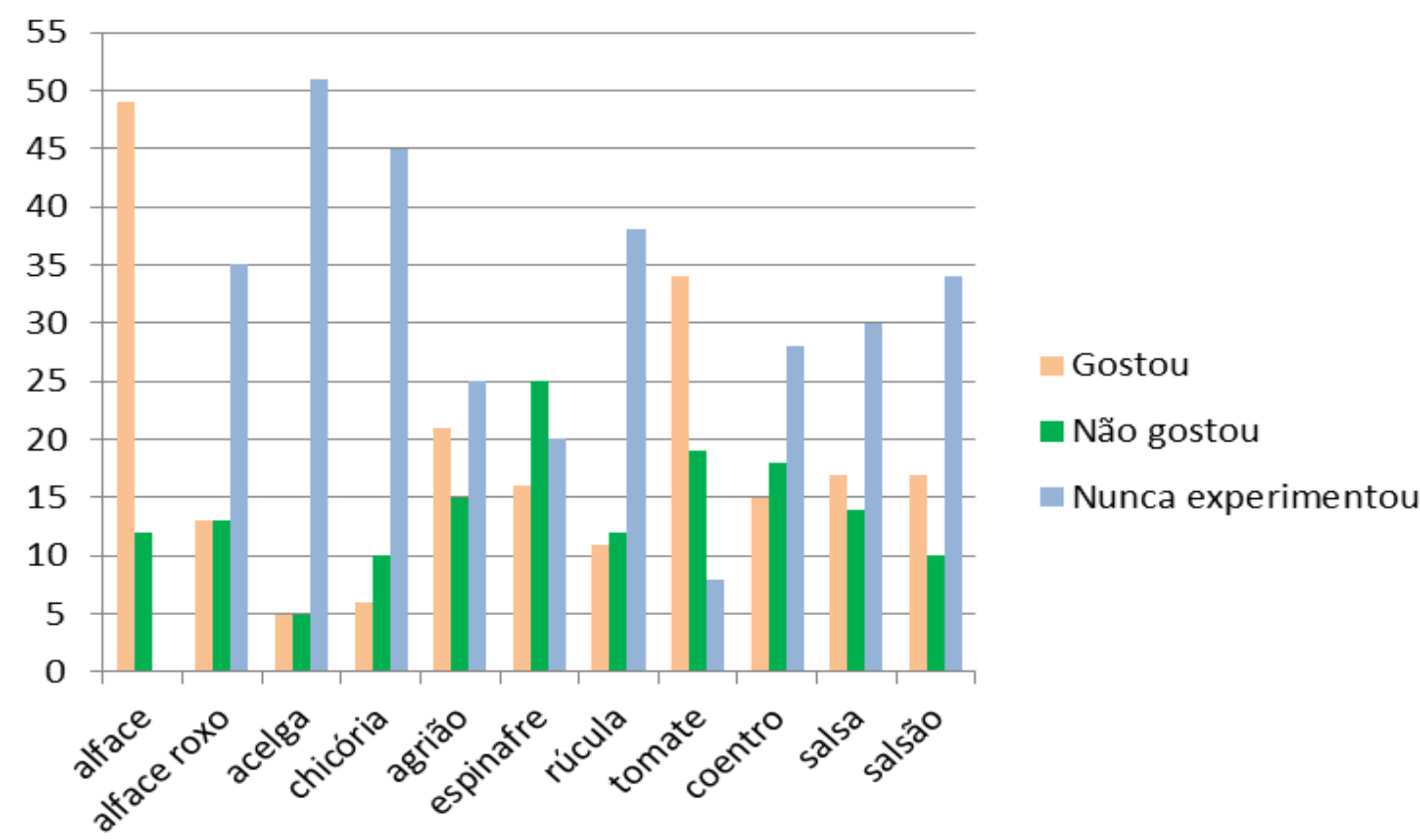

Figura 3 - Gosto e experimentação dos vegetais cultivados na horta escolar pelos alunos do sexto ano do Santa Mônica Centro Educacional.

Pode-se observar que dentre os vegetais da horta, os que os alunos mais gostam é a alface (49 alunos), seguido do tomate (34 alunos). De todos os vegetais experimentados pelos alunos, o espinafre foi o que a maioria menos gostou ( 25 alunos). Um dado que chama atenção é o expressivo número de vegetais que nunca foram experimentados pelos alunos, são eles alface-roxa (35), acelga (51), chicória (45), agrião (25), rúcula (38), coentro (28), salsa (30) e salsão (34) (Gráfico 1). A alface por sua vez, foi experimentada por todos os alunos entrevistados.

Segundo Valle e Euclydes (2007), dois fatores atuam na formação dos hábitos alimentares na infância, sendo eles (1) os fatores fisiológicos: experiências intrauterinas, paladar do recém-nascido, aleitamento materno, neofobia e regulação da ingestão de alimentos, e (2) os fatores ambientais: alimentação dos pais, comportamento do responsável, condições socioeconômicas, influência da televisão e alimentação em grupo. O "bombardeio" das campanhas publicitárias também é um fator relevante para a 
influência alimentar das crianças, fazendo com que as famílias percam a sua soberania alimentar (KING et al., 2011).

Como observado na figura 3 , a maioria dos vegetais nunca foi experimentada pelos alunos. A reação de neofobia, caracterizada como a rejeição por alimentos novos, pode estar presente na escolha dos alimentos a serem consumidos. As preferências alimentares são na maior parte aprendidas pelas experiências adquiridas com a ingestão e a comida, e ainda estão associadas com o ambiente alimentar infantil, principalmente no contexto social (BIRCH, 1999).

Segundo Garcia (2003) o comportamento alimentar depende de determinantes culturais e psicossociais, considerando-se que na sociedade moderna, principalmente urbana, o comportamento alimentar é determinado pela estrutura socioeconômica.

Quanto aos vegetais cultivados com finalidade alimentícia, há uma restrição na variedade dos alimentos, e perda da identidade regional. A mega biodiversidade brasileira é muito pouco explorada quando se trata de considerar a diversidade florística como potencial alimentício. Para atender a interesses econômicos através do desenvolvimento de monoculturas e a globalização do mercado, os seres humanos optaram pela especialização alimentar ao invés da diversificação, disponibilizando poucas espécies melhoradas a serem cultivadas por todo o mundo. A Amazônia, por exemplo, possui uma imensa diversidade de espécies frutíferas e de hortaliças. Estimase que cerca de 280 espécies possuem um potencial alimentício, em um levantamento feito na região metropolitana da cidade de Porto Alegre/Brasil, espécies essas consideradas daninhas ou inços, que medram entre as plantas cultivadas e possuem grande importância ecológica (KINUPP; BARROS, 2007).

As justificativas dos alunos quando questionados sobre o porquê não gostavam de determinadas plantas foram as seguintes: "porque é ruim", "porque não gosto do gosto", "porque me enjoa", "porque não tem gosto agradável", "porque eles tem um gosto horrível", dentre estas respostas os alunos que foram mais específicos (7) na definição do sabor mencionaram a palavra amargo na resposta "porque é amargo", "porque é ruim, o gosto é amargo".

O sabor amargo tem dois fatores principais que influenciam a sua rejeição. Primeiro o fator inato gerado por um potencial evolutivo, onde provavelmente a espécie 
evita o consumo de vegetais amargos, uma vez que os componentes que causam este sabor podem ser tóxicos como os glicosídeos cianogênicos ou alcaloides. A tolerância para este sabor pode ser menor na infância e na velhice humana. O outro fator é a variância do paladar amargo nos indivíduos, respeitando uma base genética, a partir da produção de algumas substâncias no corpo, que trazem a percepção do sabor amargo, classificando os indivíduos em três grupos, de acordo com sua sensibilidade gustativa para o sabor amargo em: muito sensíveis, moderadamente sensíveis e ligeiramente ou não sensíveis (ALMEIDA, 2010). Dessa forma, alguns vegetais quando tem seu amargor percebido, podem representar uma menor aceitação pelas crianças, através do nível de sensibilidade a este sabor (DINEHART et al., 2006). Outro fator a considerar é a disseminação, principalmente pelas pessoas mais sensíveis ao amargor, de plantas que são amargas ou ruins, o que pode influenciar na decisão de terceiros de não experimentar novos alimentos. De acordo com Wardle e Cooke (2008) as influências dos pais e do ambiente familiar são os principais fatores que contribuem para as preferências alimentares das crianças. Talvez esse seja um dos motivos do elevado número de plantas não experimentadas pelos alunos, que aparece no resultado da figura 3.

\section{Percepção sobre saúde e meio ambiente}

Os alunos foram perguntados se há diferença entre os vegetais comercializados (oriundos do hortifruti, sacolão ou supermercados) e os da horta escolar cultivada por eles. A maioria dos alunos (34) relacionou o uso do agrotóxico utilizado nos vegetais comercializados como a principal diferença, enquanto uma minoria (4) indicou que os alimentos comercializados possuem melhor qualidade e são mais limpos. Alguns alunos opinaram (23), ou seja, responderam sim ou não, mas não conseguiram justificar a resposta (Quadro 1).

Quadro 1 - Resposta dos alunos do sexto ano do Santa Mônica Centro Educacional sobre a diferença entre os vegetais comprados e os produzidos pela horta escolar.

Categorias de respostas

Número
de
respostas




\begin{tabular}{|l|c|}
\hline $\begin{array}{l}\text { Alimentos da horta possuem melhor qualidade são mais } \\
\text { naturais e sem agrotóxicos. }\end{array}$ & 34 \\
\hline $\begin{array}{c}\text { Alimentos comercializados possuem melhor qualidade, são } \\
\text { mais variados e mais limpos. }\end{array}$ & 4 \\
\hline Responderam somente sim, mas não souberam opinar. & 13 \\
\hline Responderam somente não, mas não souberam opinar. & 10 \\
\hline
\end{tabular}

Nas percepções dos alunos, as diferenças sobre a procedência dos alimentos é notória, como: "quando vai para o sacolão eles passam por um processo", "porque não tem coisa química", "porque o da horta é mais natural". Por estarem cultivando os alimentos na nossa horta, os alunos tem um maior conhecimento sobre os elementos que estão sendo utilizados, diferente dos vegetais que são comprados.

Com a horta sendo estabelecida e trabalhada no ambiente escolar, as crianças podem acompanhar, cuidar e entender que antes de chegar ao mercado os alimentos passam por todo um processo de desenvolvimento e de preparo onde são aplicadas algumas técnicas, passando assim, a ter um novo significado. Dessa forma, quando a criança tem a oportunidade de acompanhar o desenvolvimento do seu próprio alimento, há um estreitamento da distância do entendimento que os alunos têm entre uma alimentação saudável e a sua aceitação (PIMENTA; RODRIGUES, 2011).

Quando perguntados se preferiam ter uma horta em casa ou comprar as plantas no comércio (hortifruti/sacolão), 53 alunos responderam que preferiam ter uma horta em casa e 8 responderam que preferiam comprá-las. Os fatores relacionados pelos alunos que preferiram ter uma horta em casa podem ser visualizados no Quadro 2.

Quadro 2 - Respostas dos alunos do sexto ano do Santa Mônica Centro Educacional que demonstraram preferência em ter uma horta em casa.

\begin{tabular}{|l|c|}
\hline Categorias de respostas & $\begin{array}{c}\text { Número de } \\
\text { respostas }\end{array}$ \\
\hline Qualidade, saúde dos alimentos e bem-estar & 32 \\
\hline Economia de dinheiro & 17 \\
\hline Qualidade dos alimentos e economia & 4 \\
\hline
\end{tabular}

Examinando as respostas, conseguimos observar que os alunos possuem uma percepção sobre a qualidade dos alimentos que se relaciona com o cultivo. A relação de economia e boa qualidade também está presente nestas percepções como "Porque iria 
sair mais barato e de boa qualidade", "Gastaria menos dinheiro e não tem agrotóxico", e também sobre a saúde e bem-estar, "Porque é mais saboroso e não tem agrotóxicos", "Participar do cultivo".

Uma horta no ambiente escolar é capaz de sensibilizar não só os alunos, mas também todo o corpo escolar a fazer uma reflexão sobre alimentação saudável. O contato direto das crianças com a horta pode gerar uma reação que extrapola os limites da escola. Os alunos podem levar essa experiência para casa, compartilhando os sentimentos com a família e transformando em uma iniciativa para se ter uma horta em casa (PIMENTA; RODRIGUES, 2011).

Quando perguntados se o agrotóxico é bom ou ruim para a saúde e o meio ambiente e o porquê, obtivemos as categorias descritas no Quadro 3.

A maioria dos alunos foi capaz de relacionar o uso de agrotóxicos (também chamados de defensivos agrícolas) aos danos causados à saúde e ao meio ambiente: "Porque pode danificar o solo", "A planta cresce de um jeito não natural", "Porque podem trazer doenças para o ser humano" e "Porque contamina as plantas". Estas foram algumas das respostas que mostram esta percepção.

Quadro 3 - Respostas dos alunos do sexto ano do Santa Mônica Centro Educacional sobre os impactos dos agrotóxicos na saúde humana e meio ambiente.

\begin{tabular}{|l|c|}
\hline Categorias de respostas & $\begin{array}{c}\text { Número } \\
\text { de } \\
\text { respostas }\end{array}$ \\
\hline Malefícios na saúde e ambiente & 41 \\
\hline $\begin{array}{c}\text { Relacionadas a defesa do uso de agrotóxicos pela a } \\
\text { fertilização, crescimento e controle de pragas }\end{array}$ & 5 \\
\hline Disseram que é ruim, mas não justificaram. & 5 \\
\hline Disseram que é bom, mas não justificaram. & 3 \\
\hline Não responderam & 7 \\
\hline
\end{tabular}

O Brasil hoje é o maior consumidor de agrotóxicos no mundo, fazendo uso inclusive de venenos que já foram banidos em outros países por apresentarem altos índices de nocividade (BURIGO, 2016). Na medida em que avança a produção agrícola, aumenta também o consumo destes produtos, também chamados de pesticidas. Os agrotóxicos são químicos utilizados no controle de pragas e doenças vegetais, com o intuito de melhorar a produção agrícola. A falta de conhecimento sobre os riscos 
relacionados à sua utilização feita de modo extensivo e indiscriminado, o desrespeito a normas básicas de segurança, somado aos interesses lucrativos das grandes distribuidoras e produtoras destes venenos, e os problemas sociais do ambiente rural, são fatores que contribuem para os danos ambientais e à saúde dos trabalhadores (MOREIRA et al., 2002).

Os agrotóxicos quando aplicados na lavoura podem contaminar a água, o ar e o solo. Eles foram encontrados inclusive na água da chuva, na urina, no sangue humano, e no leite materno (BELO et al., 2012; MENCK et al., 2015). Estes produtos exterminam não somente as pragas como também micro-organismos não nocivos do solo, mas de grande importância ecológica, causando assim contaminações secundárias, o que acarreta um uso maior de agrotóxicos.

Estudos apontam que estes defensivos, principalmente os organofosforados e carbamatos são os que mais causam intoxicação humana. De acordo com a Organização Internacional do Trabalho/Organização Mundial de Saúde, nos países em desenvolvimento os agrotóxicos causam 70 mil intoxicações agudas e crônicas (ILO/WHO, 2005). O acúmulo destas substâncias tóxicas no corpo humano está relacionado ao desenvolvimento de doenças como Linfoma Não-Hodgkin, câncer, mal de Parkinson, depressão, má formação congênita, déficit de atenção, e até suicídios (BURIGO, 2016).

\section{CONCLUSÕES}

Os documentos da Base Nacional Comum Curricular preconizam a educação alimentar e nutricional como tema que deve ser incorporado aos currículos e as propostas pedagógicas das escolas (BRASIL, 2017). De acordo com Bissoli; Lanzillotti (1997) o desenvolvimento de práticas educativas de bons hábitos alimentares na infância podem ter reflexo na vida adulta. Nesse sentido, os resultados obtidos indicaram que a maioria dos alimentos cultivados na horta nunca foram experimentados pelos alunos, o que nos permite a reflexão da importância sobre os fatores que modelam os hábitos alimentares das crianças para criar atividades estratégicas para a sensibilização do aluno sobre os alimentos, aprendizagem sobre os diversos conteúdos 
que podem ser trabalhados nas práticas com a horta e estímulos para novas experimentações. No convívio com os alunos pode-se perceber que as crianças demonstram interesse nos alimentos dos adultos, absorvendo assim a dieta cotidiana do grupo familiar a qual estão inseridas.

Segundo Tibolla; Nactigall (2014), a horta dentro do ambiente escolar pode ser capaz de estreitar a relação dos alunos com a natureza. Com o projeto da horta escolar os alunos acompanharam de perto o tratamento dos vegetais sem defensivos agrícolas. Com o cultivo orgânico, os alunos vivenciam, através da atividade, técnicas simples e alternativas para a produção de hortaliças contrapondo o cenário nacional de utilização de agrotóxicos em grande escala, de maneira crítica e participativa. As atividades trabalhadas na horta escolar podem estimular a compreensão da importância das hortaliças para a saúde humana e mudanças significativas em seus valores, contribuindo para uma formação reflexiva dos alunos tornando-os sujeitos capazes de intervir na sua realidade social. Tristão (2004) alerta para a necessidade de se estabelecer vínculos e conexões com o cotidiano para tornar o processo de ensino-aprendizagem mais significativo aos alunos.

Foi possível observar neste trabalho a importância de se utilizar uma horta como ferramenta pedagógica para explorar a percepção dos alunos sobre saúde e meio ambiente e ampliar os seus conhecimentos, uma vez que, aplicando prática à teoria há um favorecimento para o processo de ensino-aprendizagem.

\section{REFERÊNCIAS}

ALARCÃO, I. Professores reflexivos em uma escola reflexiva. São Paulo: Corteza, 2010.

ALMEIDA, A. T. M. S. O treino do paladar: marcadores precoces de uma alimentação saudável para a vida. 2010. 37f. Trabalho de Conclusão de Curso (Monografia) - Faculdade de Ciências da Nutrição e Alimentação, Universidade do Porto, Porto, 2010. 
ALMEIDA, S. S.; NASCIMENTO, P. C. B. D.; QUAIOTI, T. C. B. Quantidade e qualidade de produtos alimentícios anunciados na televisão brasileira. Revista de Saúde Pública, São Paulo, v.36, n.3, p. 353-355, jun. 2002.

BARCELOS, V. Educação Ambiental: sobre princípios, metodologias e atitudes. Petrópolis: Editora Vozes, 2008.

BELO, M. S. S. P. et al. Uso de agrotóxicos na produção de soja do Estado do Mato Grosso: um estudo preliminar de riscos ocupacionais e ambientais. Revista Brasileira de Saúde Ocupacional, São Paulo, v. 37, n.125, p. 78-88, jan./jun. 2012.

BIRCH, L. L. Development of food preferences. Annual Review of Nutrition, v.19, p.41-62, jul. 1999.

BISSOLI, M. C.; LANZILLOTTI, H. S. Educação nutricional como forma de intervenção: avaliação de uma proposta para pré-escolares. Revista de Nutrição, Campinas, v.10, n.2, p.107-113, jul./dez. 1997.

BRASIL. Base Nacional Comum Curricular: Educação é a base. Brasília: Ministério da educação, 2017. Disponível em: http://portal.mec.gov.br/index.php?option=com_docman\&view=download\&alias=7961 1-anexo-texto-bncc-aprovado-em-15-12-17-pdf\&category_slug=dezembro-2017pdf\&Itemid=30192> Acesso em: 26 ago. 2019.

BRASIL. Parâmetros curriculares nacionais: introdução aos parâmetros curriculares nacionais. Brasília: MEC/SEF, $1997 . \quad$ Disponível em: http://portal.mec.gov.br/seb/arquivos/pdf/livro01.pdf. Acesso em: 26 ago. 2019.

BURIGO, A. Impacto dos Agrotóxicos na alimentação, saúde e meio ambiente. 2016. Disponível em: <http://www.mobilizadores.org.br/wpcontent/uploads/2016/08/CartilhaAgrotoxicos-final.pdf>. Acesso em: 17 nov. 2017.

CRIBB, S. S. P. Contribuições da educação ambiental e horta escolar na promoção de melhorias ao ensino, à saúde e ao ambiente. Ensino, Saúde e Ambiente, Niterói, v.3, n.1, p.42-60, abr. 2010.

DINEHART M. E. et al. Bitter taste markers explain variability in vegetable sweetness, bitterness, and intake. Physiology \& Behavior, v.87, p.304-13, feb. 2006. 
FREITAS, A. V. L. et al. Plantas medicinais: um estudo etnobotânico nos quintais do Sítio Cruz, São Miguel, Rio Grande do Norte, Brasil. Revista Brasileira de Biociências, Porto Alegre, v. 10, n. 1, p. 48-59, jan/mar. 2012.

GARCIA, R. W. D. Reflexos da globalização na cultura alimentar: considerações sobre as mudanças na alimentação urbana Effects of globalization on food culture: considerations on urban food changes. Revista de Nutrição, Campinas, v. 16, n.4, p.483-492, out./dez. 2003

ILO/WHO. Joint Press Release ILO/WHO: Number of Work related Accidents and Illnesses Continues to Increase - ILO and WHO Join in Call for Prevention Strategies. 2005. Disponível em: <https://www.ilo.org/global/about-theilo/newsroom/news/WCMS_005161/lang--en/index.htm>. Acessado em: 23 ago. 2019.

KING, L. et al. Industry self regulation of television food advertising: Responsible or responsive? International journal of pediatric obesity, v.6, n.2, p.390-98, jun. 2011.

KINUPP, V. F.; BARROS, I. B. I. Riqueza de Plantas Alimentícias Não-Convencionais na Região Metropolitana de Porto Alegre, Rio Grande do Sul. Revista Brasileira de Biociências, Porto Alegre, v. 5, supl. 1, p. 63-65, jul. 2007.

MENCK, V. F.; COSSELLA, K. G.; OLIVEIRA, J. M. Resíduos de agrotóxicos no leite humano e seus impactos na saúde materno-infantil: resultados de estudos brasileiros. Segurança Alimentar e Nutricional, Campinas, v. 22, n.1, p. 608-617, 2015.

MIRANDA, P.M. et al._A educação ambiental nas escolas públicas de Ituiutaba-MG: diferentes enfoques, diferentes olhares. In: VIII ENCONTRO NACIONAL DE PESQUISA EM EDUCAÇÃO EM CIÊNCIAS E I CONGRESSO IBEROAMERICANO DE INVESTIGACIÓN EM ENSEÑANZA DE LAS CIÉNCIAS, 2011, Campinas. Anais eletrônicos... Campinas: ABRAPEC, 2011. Disponível em: 〈http://abrapecnet.org.br/atas_enpec/viiienpec/resumos/R1696-1.pdf>. Acesso em: 28 out. 2019.

MONTEIRO, C. A.; CASTROM I. R. R. Por que é necessário regulamentar a publicidade de alimentos. Ciência e Cultura, São Paulo, v.61, n.4, p.56-59, 2009. 
MOREIRA, C. J. et al., Avaliação integrada do impacto do uso de agrotóxicos sobre a saúde humana em uma comunidade agrícola de Nova Friburgo, RJ. Rev. Ciência \& Saúde Coletiva v.7, n.2, p.299-311, 2002.

MUNIZ, V. M.; CARVALHO, A. T. O Programa Nacional de Alimentação Escolar em municípios do estado da Paraíba: um estudo sob o olhar dos beneficiários do programa. Revista de Nutrição, Campinas, v.20, n.3, p. 285-296, maio/jun. 2007.

NEVES, M. I. S. C. Projeto Horta Escolar. Secretaria Municipal de Educação Prefeitura Municipal de Mogi das Cruzes-SP, 2006. Disponível em: <https://www.passeidireto.com/arquivo/6031640/projeto-horta-escolar $>$. Acesso em 26 de ago. 2019.

PERSON, V. A.; GÜLLICH, R. I. C. Investigação-ação em Ciências: a reflexão como categoria formativa de professores. In: VI ENCONTRO REGIONAL SUL DE ENSINO DE BIOLOGIA (EREBIO-SUL) E XVI SEMANA ACADÊMICA DE CIÊNCIAS BIOLÓGICAS, 2013, Santo Ângelo. Anais eletrônicos... Santo Ângelo: Universidade Regional Integrada do Alto Uruguai e das Missões, 2013. Disponível em: $<$ http://santoangelo.uri.br/erebiosul2013/anais/wp-

content/uploads/2013/07/comunicacao/13376_59_Vanessa_Aina_Person.pdf>. Acesso em 28 out. 2019.

PIMENTA, J. C; RODRIGUES, K. S. M. Projeto horta escola: ações de educação ambiental na escola Centro Promocional Todos os Santos de Goiânia (GO). In: II SEAT - SIMPÓSIO DE EDUCAÇÃO AMBIENTAL E TRANSDISCIPLINARIDADE, 2011, Goiânia. Anais eletrônicos... Goiânia: UFG/ IESA/ NUPEAT, 2011. Disponível em: <https://nupeat.iesa.ufg.br/up/52/o/29_Horta_na_escola.pdf $>$. Acesso em: 23 ago. 2019.

SILVA, C. R.; GOBBI, B. C.; SIMÃO, A. A. O uso da análise de conteúdo como uma ferramenta para a pesquisa qualitativa: descrição e aplicação do método. Organizações Rurais \& Agroindustriais, Lavras, v. 7, n. 1, p. 70-81, 2005.

THIOLLENT, M. Metodologia de pesquisa-ação na área de gestão de problemas ambientais. Revista Eletrônica de Comunicação Informação \& Inovação em Saúde, Rio de Janeiro, v.1, n.1, p.93-100, jan.-jun. 2007. 
TIBOLLA, S. S.; NACTIGALL, G. R. Educando com a horta pedagógica. Revista Extensão Tecnológica, Santa Catarina, n.1, p. 157-161, 2014.

TRIPP, D. Pesquisa-ação: uma introdução metodológica. Educação e Pesquisa, São Paulo, v. 31, n. 3, p. 443-466, set./dez. 2005.

TRISTÃO, M. Saberes e fazeres da educação ambiental no cotidiano escolar. Revista brasileira de educação ambiental, Brasília, n.0, p. 47-55, nov. 2004.

VALLE, J. M. N.; EUCLYDES, M. P. A formação dos hábitos alimentares na infância: uma revisão de alguns aspectos abordados na literatura nos últimos dez anos. Revista de APS, Juiz de Fora, v.10, n.1, p. 56-65, jan./jun. 2007.

VIÉGAS, A.; GUIMARÃES, M. Crianças e educação ambiental na escola: associação necessária para um mundo melhor? Revista brasileira de educação ambiental, Brasília, n.0, p. 56-62, nov. 2004.

WARDLE, J.; COOKE, L. Genetic and environmental determinants of children's food preferences. British Journal of Nutrition, n. 99, suppl. 1, p.15-21, feb. 2008.

ANEXO 1: Questionário aplicado aos alunos.

Nome do aluno: ano escolar:

Idade:

1 - Você já plantou ou cuidou de alguma planta antes?

( ) $\operatorname{sim}$ ( ) não

2 - Em caso positivo, quais foram os seus cuidados?

3 - Já preparou ou esteve em contato com uma horta antes? Onde?

4 - Em sua casa já teve uma horta?

( ) Sim. O que foi plantado nela, você se lembra?

Recebido em: 02/05/2019

Aceito em: 01/10/2019 
( ) Não. Por qual motivo?

5 - Observe os vegetais que serão cultivados em nossa horta escolar:
1. Alface
3. Acelga
5. Agrião
7. Rúcula
9. Coentro 11

Salsão
2. Alface roxa
4. Chicória
6. Espinafre
8. Tomate
10. Salsa

De acordo com os vegetais da nossa horta, listados acima, preencha a tabela abaixo:

Vegetais que gosto Vegetais que não gosto Vegetais que nunca experimentei

6 - Tem algum vegetal da horta, que você não gosta? Por quê?

7 - Tem algum vegetal que você gostaria de cultivar em nossa horta?

8 - Você acha que tem diferença dos vegetais comprados no hortifruti ou sacolão daqueles que são produzidas em nossa horta escolar?

9 - Se você pudesse escolher o que iria preferir

( ) Ter uma horta em casa. Por quê?

( ) Comprar as plantas no sacolão. Por quê?

10 - Você sabe o que é agrotóxico?
( ) $\operatorname{Sim}$
( ) Não

11 - Em caso positivo, você acha que este produto pode ser bom ou ruim para a saúde e o meio ambiente? 
( ) bom, por quê? ( ) ruim, por quê?

12 - Você come vegetais:

( ) todo dia

( ) uma a três vezes por semana

( ) uma vez por mês

( ) nunca

( ) não se lembra

13 - De todos os vegetais que você já experimentou, quais você mais gosta?

14 - De todos os vegetais que você já experimentou, quais você não gosta? 